\title{
Efficiency evaluation criteria of communication paths structure in a complex of buildings of maternity and child-care institutions
}

\author{
Valery Kholshchevnikov ${ }^{1, *}$, Dmitry Korolchenko ${ }^{1}$ and Olesya Zosimova ${ }^{1}$ \\ ${ }^{1}$ Moscow State University of Civil Engineering, Yaroslavskoe shosse, 26, Moscow, 129337, Russia
}

\begin{abstract}
The communication paths form the network of areas that connect the public spaces of the building among themselves and with external (in relation to the building) sources and accumulators of crowd flows. The spaces can have different purposes of use. The function of the communication paths is always the same - ensuring the safe movement of crowd flows. That's why communication paths are one of the security systems of buildings, constructions and associated areas under various application conditions. The areas of communication path can be different types: horizontal, stairs down, stairs up, ramps, openings. Its effective size is determined in accordance with values of crowd flow movements. They can vary depending on numerous factors, but represent the result of invariant patterns of connection between parameters of flows which have different composition. The article considers the calculated values which determine the criteria of optimality of the size of communication paths of buildings using the buildings of maternity and child-care institutions in their multifunctional use as an example.
\end{abstract}

\section{Introduction}

Buildings of maternity and child-care institutions are the elements of the material structure of the system of state's health and welfare protection of mother and children carrying the future of the country. It's nomenclature and purpose of use are determined by development of healthcare in state. In our country the modern basics of health protection of mother and child were formed in 1920-s - the Division of maternity and infancy was created in people's commissariat. All the existing medical institutions to support mother and child were placed under Division's leadership. By 1920 the 108 baby houses, 267 orphanages for infants and homes for children up to three years were created in Russia. Thereby the socioeconomic problem was being solved - the engagement women in social production. By 1930s the three-tier system of maternity and child-care was formed in USSR: women's consultations, who perform diagnosis of pregnancy and prenatal care, the treatment of women with gynecological diseases; maternity hospitals; child health centers, where pediatricians see and treat children since the time they are discharged from the maternity hospital and up to 15 years. The principles of constructing such three-tier system remain

* Corresponding author: ikbs@,mgsu.ru 
until now. But over the past decades its contents was being changed in accordance with changing socio-economic conditions of Russian society. The system of maternity and childcare developed intensively in 1940-1980s: the network of healthcare institutions was developed, which provided therapeutic care to children and mothers, the number of qualified obstetricians and pediatricians was grown, and the new technologies were introduced. But the sharp fertility decline after the Fall of USSR had result in situation where women's consultations had to refocus their work on treatment of gynecological patients and prevention of artificial abortion the number of which had increased significantly. Socio-economic metamorphosis affected the health of children too.

Currently, the maternity and child-care service in Russia is gradually recovering as a self-direction of healthcare introduced by the institutions, which provide obstetric and gynecological care to women, treatment-and-prophylactic help to children and the complex of social and legal measures to support motherhood and childhood. It includes 15.5 thousand of outpatient facilities (women's consultations, child health centers and dispensaries), 478 children's hospitals ( 87.4 beds per 10 thousand children aged 0 to 14 years), residential institutions (101.8 thousand beds for pregnant and parturient women, 109.4 thousand beds for gynecological patients). In addition to the above the availability of pediatricians is 25.6 per 10 thousand children, and of obstetricians -5.4 per 10 thousand women. The diverse structure of maternity and child-care institutions (perinatal centre; maternity hospital; women's consultation, family planning center and reproduction; center of reproductive health of adolescents; the children's home, including specialist; dairy) requires a large number of buildings and structures for its accommodation, that meet functional and technological requirements of the process of medical care for these sociodemographic groups and provide comfortable values of microclimate parameters of the rooms $[1,2]$. Its construction, reconstruction and operation requires a significant financial and material-and-technical contributions, which are always "running out", not only in the state but also among entrepreneurs and sponsors. That's why the search of principles to improve the technical and economic efficiency of design consideration of the building of maternity and child-care institutions (as well as other types of buildings) remains the vital task. The experience of architectural design of building and its operation shows the direction of the search - it is their placement in complex, which allows rational operation of functionally homogeneous spaces and cooperation of life-support system of buildings and structures that have the similar purpose of use. It is well known [3] that combining buildings into a single complex reduces: the necessary building footprint area by $30-40 \%$, working and rentable area of buildings by $10-15 \%$, the cost of construction by $4-10 \%$, operating costs by 5-6\%. (In modern terms should be considered as the result of combining buildings into complex and the possibility of increasing of technical equipment of the access points and the reliability of anti-terrorist protection of buildings and associated areas).

In addition to the above it is noted that when placing buildings in a single complex the greatest effect can be achieved by optimization of space-planning decisions. As the area of communication paths is about $30 \%$ of the total area of buildings [4] and they, in fact, determine the structure of space-planning decisions, the analysis of the calculated values that determine the rationality of the areas of communication paths structure in the buildings of the complex of maternity and child-care institutions, becomes paramount.

\section{Methods}

The building is the amount of space framed in the natural environment by system of structural units, to create the artificial environment inside required for life and human activity. It is impossible to create the required optimum conditions of the artificial 
environment for the human life and activities in the building without utility systems and services: heating, ventilation, air conditioning, water, sewer, electricity, garbage disposal etc. So the modern building is always a complex of life-support systems.

The spaces in the building of motherhood and childhood institutions can have different functional and technical purpose of use, but their purposes don't change in different modes of operation, and thus the size of these rooms is determined by the stable values of the parameters of their operation, for example [5], in normal conditions. The function of communicational path is always the same - ensuring the safe movement of crowd flows as they move between specific areas of the building and external sources of accumulation and generation of flows. To determine the area of communication paths it is necessary to know quantity of people who can use them in both cases simultaneously. From this point of view the areas of the building of maternity and child-care institutions can be divided into premises intended for permanent human habitation (the chamber for the maternity, wards for newborns) and the premises operated only during the working day. Premises operated during the working day, can have variable or constant composition of people there. In the first case, it is staff (e.g., laboratories, administrative offices). In the second case, it is flow of visitors (for example, doctors' offices, and waiting rooms near registration). Existing standards don't consider this aspect of operation without permanent human habitation there. When determining the calculated number of occupants in such premises they are based on the minimum estimated area per one person constantly staying here, which is set by technological standards of workplace organization. That is why MGSN 4.19-2005, for example, demanded increase the estimated number of people in office spaces by $25 \%$ [6]. It is obvious that in all these cases it is necessary to consider temporal dynamics of flows of people visiting buildings and premises of different functions within 24 hours [7-9].

But the calculated values which determine the optimal size of communicational paths and their structure are dramatically change under various application conditions of building. Communication paths should ensure the comfort movement of people during their everyday stay in the building, free movement of people in the case of organization of their preliminary (preventive) evacuation from a building when emergency situations caused by natural disasters or threatening terrorist actions approach, unhindered and timely simultaneous evacuation of people in case of technogenic accident and fire [10]. At the beginning of a fire the vast majority of communication paths is used as emergency routes and exits if they meet the submitted requirements, and then they work as a fire protection system of the building and structures [11]. Therefore, in any mode of operation of the building its communication paths should have the size large enough to provide two conditions for the process of crowd flows movement:

- crowd density on each area $\left(D_{i}\right)$ should not exceed permissible value $\left(D_{\text {per }}\right)$

$$
D_{i} \leq D_{\text {per }}
$$

- the travel time in each of the sections (ti) should not exceed values defined by the physiological capabilities of the person $\left(\mathrm{t}_{\mathrm{ad}}\right)$

$$
t_{i} \leq t_{a d}
$$

These general requirements are concretized in accordance with the operational situation. For example, the value $\mathrm{D}_{\mathrm{ad}}$ for everyday operating conditions is determined by the requirement to ensure the comfort movement of people (Table 1) and for healthy adults is no more than 0.5 person/ $\mathrm{m} 2$, and in case of evacuation in emergency situations -5 persons/ $\mathrm{m}^{2}$ while their movement along the horizontal sections of evacuation routes and 4 persons/ $\mathrm{m}^{2}$ when driving on the stairs ( Figure 1), since $D_{i}$ is above these values the clusters with 
high density can appear on the boundary of sections, in this case compressive asphyxia of the organism is possible $[12,13]$.

Table 1. Characteristics of comfort levels [4,12].

\begin{tabular}{|c|c|c|c|}
\hline $\begin{array}{l}\text { Density, } \\
\text { persons/ } \mathbf{m}^{2}\end{array}$ & $\begin{array}{c}\text { Comfort } \\
\text { level }\end{array}$ & $\begin{array}{l}\text { Distance } \mathrm{I}_{\mathrm{o}} \\
\text { between } \\
\text { people, } \mathrm{m}\end{array}$ & Characteristics of the level \\
\hline \multicolumn{4}{|c|}{ Horizontal face. The movement. } \\
\hline 0.3 & A & - & Free movement and choice of directions. \\
\hline 0.4 & B & - & Free movement and choice of directions. \\
\hline 0.7 & $\mathrm{C}$ & - & Free movement and choice of destinations is limited \\
\hline 1.1 & $\mathrm{D}$ & - & Individual speed is limited. Flow movement. \\
\hline 2.2 & $\mathrm{E}$ & - & $\begin{array}{c}\text { There is frequent change of rhythm of the movement. } \\
\text { Moving forward with high speed is possible only by } \\
\text { maneuvering. }\end{array}$ \\
\hline$>2.2$ & $\mathrm{~F}$ & - & Frequent unavoidable contact with others. \\
\hline \multicolumn{4}{|c|}{ Horizontal face. Congestion, queue, waiting area. } \\
\hline 0.8 & A & $>1.2$ & Free movement in the waiting area \\
\hline 1.1 & B & $1.1-1.2$ & $\begin{array}{l}\text { Limited movement in the waiting area with no contact } \\
\text { with others }\end{array}$ \\
\hline 1.5 & $\mathrm{C}$ & $0.9-1.1$ & $\begin{array}{l}\text { Limited movement in the waiting area with contact } \\
\text { with others }\end{array}$ \\
\hline 3.6 & $\mathrm{D}$ & $0.6-0.9$ & $\begin{array}{l}\text { Location without point contacts with others is not } \\
\text { possible. }\end{array}$ \\
\hline 5.4 & $\mathrm{E}$ & $<0.5$ & Location with frequent contact with others \\
\hline$>5.4$ & $\mathrm{~F}$ & physical contact & Close physical contact with others \\
\hline
\end{tabular}

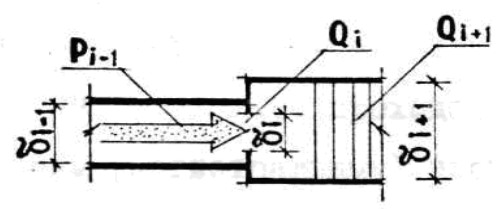

Conditions for unhindered movement:

$$
P_{i-1}<Q_{i} \leqslant Q_{i+1}
$$

$\delta_{i} \geqslant \frac{q_{i-1} \delta_{i-1}}{q_{i, \max }}$

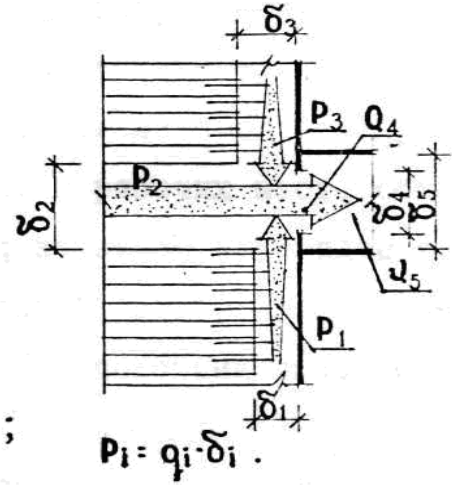

Fig. 1. The determination of required width $(\delta)$ of neighboring plots of communication paths for ensuring the unhampered movement of crowd flows $P=q \delta$ - the value of flow, q- intensity of crowd flow, $\mathrm{Q}$ - capacity of cross-sectional area of the path. 
The time of the movement during the evacuation in case of fire is limited by the value $t_{\max }$, which is determined by the dynamics of the spread of dangerous factors of fire on areas of the escape route, i.e. in this case $t_{\mathrm{ad}}=t_{\max }$. Thus the critical length of the escape route $(L)$ at each of its stages should not exceed the values:

$$
L=V_{j} t_{\max }
$$

$V_{i j}$ - the speed of movement of crowd flow on the site (i) of relevant type of the way $(j)$, $q_{i}=V_{i j}$ - intensity of its movement on this type of the way.

In normal conditions of building operation the critical length of the areas of communication paths is determined by intensity of connection between separate spaces and physical abilities of people; for example the stairway is limited to four storey's - in residential buildings over five stories the installation of an Elevator is required.

The area of communication paths (Figure 2) in General is determined by the requirements (1), (2) and their scheme which is typical for buildings of particular functional purpose of use.

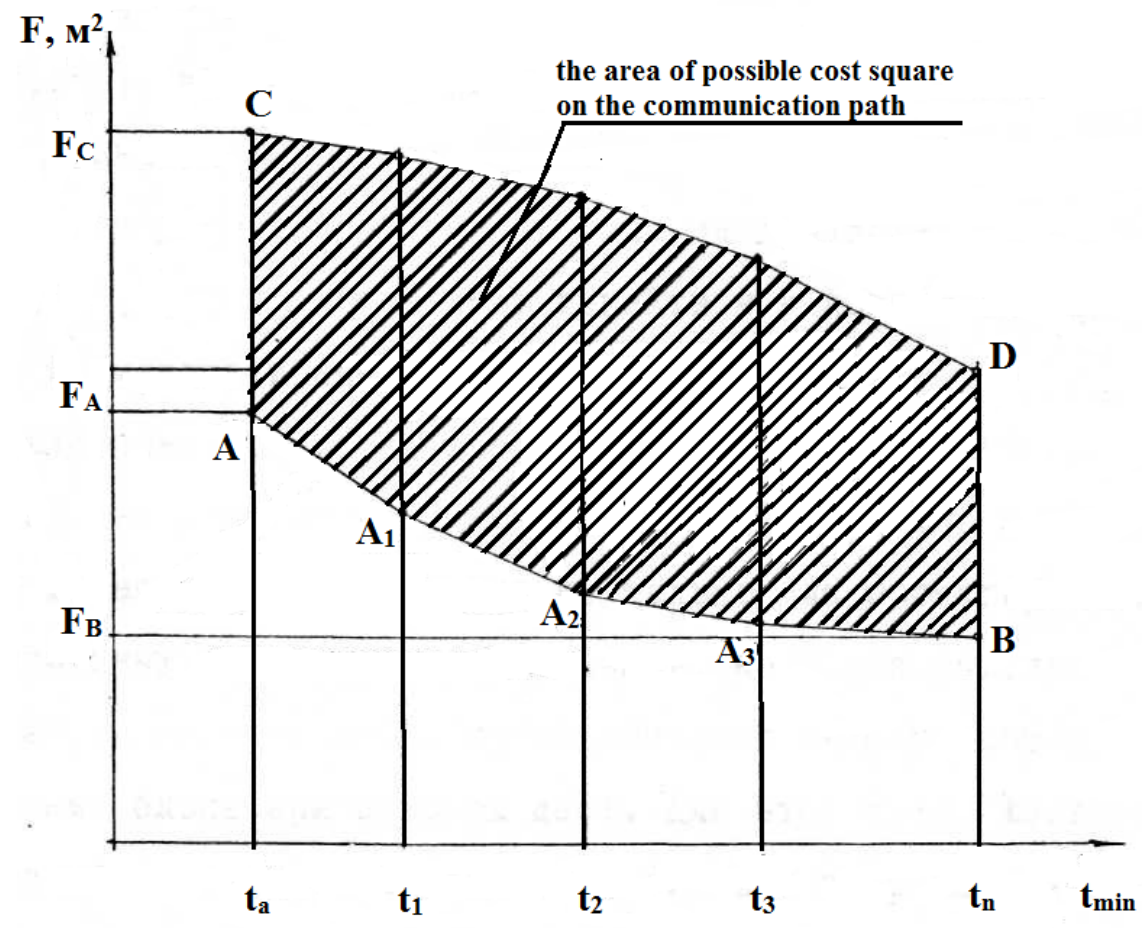

Fig. 2. The scheme of possible solution region in case of optimization of the area of communication path in building, where $\mathrm{F}$ - area; $\mathrm{t}=1 / \mathrm{v}-$ time.

Complex of maternity and child-care institutions includes the buildings of different functional fire hazard classes and purposes of use [11]:

F1.1 - maternity departments, operational units, emergency Department, ward offices, branch of newborns, intensive care unit;

F 3.4 - units for inpatient and outpatient patients location (polyclinics, consultation, diagnostics, medical rehabilitation, blood transfusions, day hospitals, office of in vitro fertilization, etc.); 
F 4.2 and F 4.3 - administrative departments, clinical departments (administration, meeting rooms, canteen for the staff, cloakroom for the staff);

F 5.1 and F 5.2 - support departments:

- clinical diagnostic laboratories, mortuaries, Central sterilization departments, hospital pharmacies, medical archives;

- field service - economic units - kitchens, laundries, disinfecting offices, space storage (Central linen, etc.);

- items of waste treatment, maintenance workshops, closed Parking.

The analysis of space planning decisions of the buildings of maternity and child-care institutions shows that for 5 floor plans of different purpose (enfilade, atrium, hall, corridor, section) $[14,15]$ formed by centuries-old practice of structural engineering, the corridortype arrangement is favored.

This scheme is correct for evacuation of people under conditions of one-way movement and non-admittance of counter and cross human flows, this factor simplifies the search of optimal variants of DER. But in view of variety of factors which affect the size of communication path the determination of its optimal value - is multifaceted task.

The experience of its theoretical solution using linear programming algorithms and the seemingly specialized methods of the mathematical theory of flows in networks [16] has shown that for unhindered evacuation from the building (Figure 1) it is necessary to use the modification of these methods. This is so because after merger and reorganization the speed of movement of the crowd flows changes, whereas the speed of flow according to mathematical theory doesn't change; the section time is also remains the same regardless of the magnitude of flows moving through the section.

It was set that the optimal size of communication path designated for long-term movement of crowd flows is not the best for short-term movement of flows during the evacuation.

It is considered in designing that the requirements of organization of evacuation are more "hard" than requirements imposed by other operating conditions of buildings. Is it really so? The obvious example - pedestrian facilities of underground stations $[17,18]$ shows that this is not the case.

Here, the size of the communication paths should be designed on the basis of existence of flows of people arriving at the station and leaving it simultaneously. In a fire emergency, the entrance to the station is blocked and, thus, evacuating people can use the communication paths intended for people being off the station.

Then, in case incoming and out coming flows of passengers at the station are equal, in a fire emergency the available width of evacuation route and exits turns out to be two times wider than it was under the condition of one-way evacuation of out coming people. 


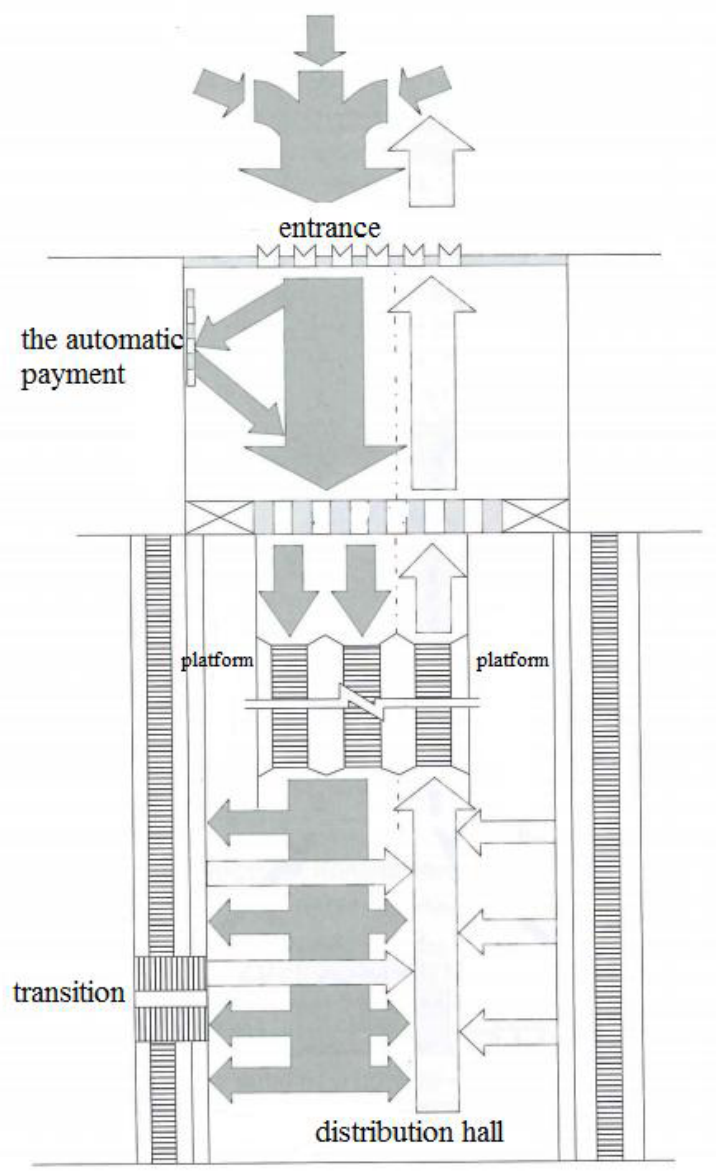

Fig. 3. The scheme of human flows movement in subway.

In schemes not only stairs, but also elevator installations are indicated as vertical evacuation routes, because in the version of July 10, 2012 of the Federal Law No. 123 "Technical Regulations on fire safety requirements" in the Article 89, the following item has appeared: "15.

To evacuate population with limited mobility from all floors of buildings it is assumed to arrange safety areas, where such category of people can stay till arrival of rescue teams, on the floors near the lifts, designed for groups of people with reduced mobility; and (or) safety areas, where such category of people can stay till arrival of rescue teams, in the staircases.

At that, the given elevators have the same requirements as the elevators for transportation of fire-fighting units have. Such elevators can be used for evacuation of people with limited mobility during a fire accident".

The necessity to use elevators for evacuation of people from high-rise buildings was shown still in 1969 [19, 15,20]. In the regulations such necessity is actually regulated by SNIP 35-01-2001 [21], because otherwise most of the buildings, and even low-rise buildings, are not available for people with little mobility. It is obvious that buildings of maternity and child-care institutions fall into this category. 


\section{Results}

As it is seen from the design scheme of movement of people while everyday operation not only the inverted crowd flows, that require the increase of the width of communication path (of the same values of densities) by $15 \%$ [20], but also intersecting flows, the density in the area of the intersection of which should not exceed 0,2 [22,23], can appear. Therefore, the area of emergency route should be more than the baseline minimum area to be timely and unhindered during the organization of emergency evacuation. In these conditions the curve of optimal solutions will be lying above the curve $\mathrm{AB}$ in figure 2, which is relevant to minimum area of evacuation routes and maximum allowable $t_{e v} \leq t_{\max }$. In addition the value of $t_{e v}$ will be under the maximum-permissible value because the widest width of the shortest evacuation route, in accordance with established [24,25] patterns $V=\varphi(D)$, lets people move with higher speed.

\section{Discussion}

The buildings of maternity and child-care institutions are differentiated by their functional purpose. The composition of the flows is formed from specific groups of people, the movement patterns of which were set recently or have not yet been studied [26]. Their characteristics are primarily "female" human flows, consisting of healthy young women and pregnant women, who should be referred to the people with limited mobility; women with children of different ages; preschool- and school-aged children. Whereas the patterns of connection between parameters of movement of preschool and school-aged children are quite well-studied [27-32], this is not true for «women-only» crowd flows, which don't exist in present classification of the crowd flows composition [33]. They also don't exist in the international scientific-technical reports.

It must be emphasized that special gender studies [34,35] have shown that psychologically women perceive a fire hazard more heightened than men, and women, unlike men, are inclined to respond to its threat inadequately. Therefore, there is reason to believe that pregnant women will respond to the threat of approaching natural catastrophic events more acutely. But we can assume (nobody still studied it) that in a normal situation there is psychophysical differentiation of response of women, being in different stages of pregnancy, to changes of the flow density, especially, in different kind of paths, which is induced by the peculiarities of ergonomics of movement along these paths. But these aspects of women behavior have never been explored. The values of pregnant women movement parameters, given in the latest edition of the Federal Law No. 123 [36], apply only to the density of human flows $\mathrm{D}<0.05$, at which they moved in comfortable and peaceful state being far from any threat of emergencies.

Significantly, the changes of anthropometric and physical characteristics of people observed in last decades in all developed countries make the vendors of software and computing systems of the crowd flows, focus on the area of the horizontal projection of the person [37], which is traditionally considered in national standards of fire safety [38-40]. In buildings of maternity and child-care institutions such changes of the value of calculated area of the person are abandoned. However, in researches these values are determined by the parameters of the person in static position. But people while moving are always swinging, and even while standing in a queue, they're shifting from foot to foot, because of the need of blood circulation in the body. These characteristics of human behavior should be taken into consideration to determine the area of the horizontal projection of the person within the crowd flow (Figure 4), especially women on different pregnancy stages. 


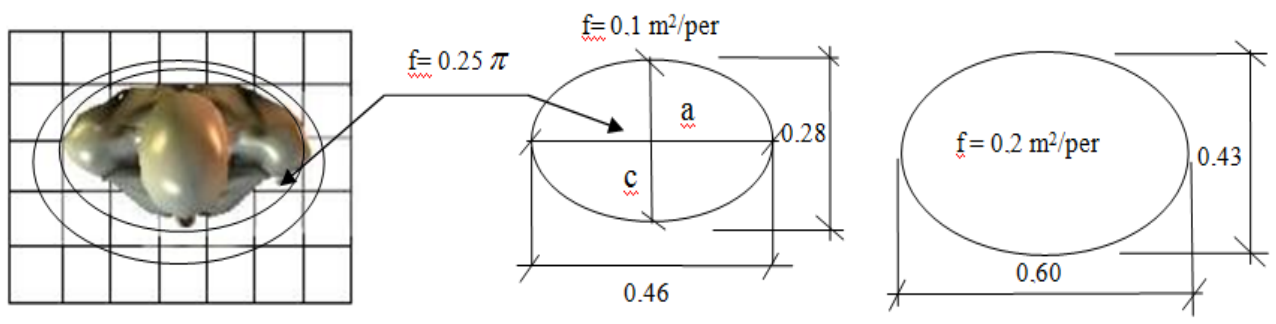

Fig. 4. Determination of the area of the horizontal projection of the person (f, $\left.\mathrm{m}^{2} / \mathrm{per}\right)$ : person in "light", home clothing, in static position [4]; the minimum individual space for a person in outerwear with his swinging while moving or "shifting" from foot to foot during prolonged standing.

\section{Conclusions}

Thus, the analysis of the principles of structural engineering of buildings of maternity and child-care institutions has shown the technical and economic feasibility of their cityplanning placement as a part of the complexes. This factor enables to significantly reduce the operation costs by:

- cooperative use of engineering systems

- improving efficiency of use of administrative facilities and medical equipment of departments common to institutions of different profile included in the complex

- reduce:

- construction cost

- build-up area

- total area of the building

- raise the level of anti-terrorist protection of areas and buildings

Moreover, the search of efficient space planning decisions of the structure of communication paths in complex of buildings occupying up to $30 \%$ of their total area should be based on:

- criteria of comfortable everyday using these paths by visitors, consisting mainly from young women of working age in the different pregnancy stages and women in a state of physiological diseases with preschool- and school-aged children,

- and criteria of unhindered and timely evacuation in emergency situations particularly during a fire.

Analysis of the relationship of these criteria shows that the width of the communication path should be designated in accordance with the acceptable level of comfort (Table 1), its length is determined by the conditions of ensuring the timely evacuation (2) of the most sedentary demographic group of visitors in case of emergency. On the assumption of the set $[25,33,39,42,43]$ invariance of a function $V=(D)$, the speed $(\mathrm{Vj})$ is determined by the general pattern:

$$
V_{j D i}^{e}=V_{j .0}^{e}\left[1-a_{j} \ln \left(D_{i} / D_{0 j}\right)\right] \text {, where } D_{i}>D_{0 j} ; V_{j . D i}^{e}=V_{j .0}^{e} \text { where } D_{i} \leq D_{0 j},
$$

$V_{\text {эj.Di }}$ - speed, depending on the density, $\mathrm{V}_{\text {ej. } .0}$ - free running speed, a - ratio, $\mathrm{D}_{\mathrm{i}}$ - crowd density on each area, $D_{0 \mathrm{j}}$ - density of the free movement.

Where the value $D_{0 j}$ determines:

$$
l_{o}=1 / D_{0 j}
$$


$1_{0}$-distance lo between people, $D_{0 j}$ - density of the free movement, the baseline minimum distance between people, which ensures the possibility of free movement and comfort.

As the values in the right part of Equation 5 are determined by now for preschool- and school-aged children [44-46,32,33], it is necessary to undertake the study of patterns of movements of flows of very specific composition ("female flow" and movement of women with children) which have never been studied before. The results of these studies will enable to start the development of difficult methodology of designing the optimal network of communication paths in buildings of maternity and child-care institutions.

\section{References}

1. V.V. Holschevnikov, A.V. Lukov, Association of construction universities (ACU, Moscow, 2001)

2. A.K. Soloviev, Physics of the environment (Moscow, 2008)

3. Recommendations for the design of complexes of community centers of urban-type villages (Stroyizdat, Moscow, 1989)

4. V.M. Predtechensky, A.I. Milinsky, Design of buildings in view of organization of human flow movement (Stroyizdat, Moscow, 1999)

5. A. Teut, G. Nedeljkov, Die cruppenpraxis (Moscow, 1993)

6. MGSN 4.19-2005 (2005)

7. P.G. Buga, Study of pedestrian movement in cities (MICE, Moscow, 1993)

8. P.G. Buga, Pedestrian movement in cities (MICE, Moscow, 1993)

9. D.A. Korolchenko, V.V. Holschevnikov, Fire and explosion safety, 8 (2015)

10. Federal Law No. 348-FZ (2016)

11. Federal Law of the Russian Federation No. 123-FZ (2008)

12. J.J. Fruin, Pedestrian planning and design (Metropolitan Association, New York, 1971)

13. V.A. Kopylov, Study of parameters of movement of people during the forced evacuation (MICE, Moscow, 1994)

14. A.V. Zakharov, Architecture of civil and industrial buildings (Stroyizdat, Moscow, 1993)

15. V.V. Holschevnikov, Optimization of routes of movement of crowd flows. High-rise buildings (MICE, Moscow, 1999)

16. L.R. Ford, D.R. Fulkerson, Flows in networks (Mir, Moscow,1996)

17. V.V. Holschevnikov, To develop and implement the new space-planning and constructive solutions of stations and hubs of the underground taking into account high speed movement of trains (MICE, Moscow, 1989)

18. I.I. Isaevich, Development of the foundations of multivariate analysis of space (MICE, Moscow, 1990)

19. L.B. Velikovsky, V.V. Holshevnikov, Evacuation from high-rise buildings (Moscow, 1969)

20. V.V. Holshevnikov, Evacuation of people from high-rise buildings (MSUCE, Moscow, 2011)

21. SNiP 35-01-2001 (2001) 
22. R.G. Grigoryants, The study of the long-existing crowd flows (MSUCE, Moscow, 1971)

23. V.S. Gvozdikov, Regularity of crowd flows in transport infrastructure and communication facilities (Moscow, 1998)

24. V.V. Holschevnikov, Crowd flows in buildings, constructions and associated areas (MICE, Moscow, 1983)

25. Patterns of connection between parameters of flows (Russian Academy of natural Sciences, Moscow, 2005)

26. O.S. Zosimova, Features of fire safety protection in institutions of maternity and childhood (MSU, Moscow, 2016)

27. V.V. Kuibyshev, Research and calculation of the patterns of movement of students (MICE, Moscow, 1995)

28. M.A. Eremchenko, Movement of crowd flows in school buildings (Moscow, 1978)

29. V.V. Kuibyshev, Safety standards for evacuation from school buildings, particularly in areas prone to natural disasters (MICE, Moscow, 1999)

30. V.V. Holschevnikov, Fire science, 18 (1980)

31. D.A. Poloz, Method of determination of the estimated time of evacuation of inhomogeneous flows from auditoriums (Minsk, 2010)

32. A.P. Parfenenko, Standardization of fire safety requirements for evacuation routes and exits in buildings of preschool educational institutions (Moscow, 2012)

33. D.A. Samoshin, Composition of flows and parameters of their movement during the evacuation (Academy of State fire service of EMERCOM of Russia, 2016)

34. ISO TR 16738 (2009)

35. O.Y. Demchenko, Y.S. Gazizova, Fire-and-explosion safety, 1 (2015)

36. The order of EMERCOM of Russia from 30.06.2009 № 382

37. P. Thompson, D. Nilsson, K. Boyce, D. McGrath, Fire Safety Journal, 1 (2015)

38. SNiP II-2-80 (1981)

39. A.F. Sharovarnikov, D.A. Korolchenko, Applied Mechanics and Materials, 1 (2014)

40. V.A. Markeev, S.S. Voevoda, D.A. Korolchenko, Oil Industry, 9 (2006)

41. D.A. Korolchenko, E.N. Degaev, A.F. Sharovarnikov, International conference on material engineering and application, 17-22 (2015)

42. D. Korolchenko, A. Tusnin, S. Trushina, A. Korolchenko, Applied Engineering Research, 21 (2015)

43. D. Korolchenko, S. Voevoda, MATEC 86, 04056 (2016)

44. D. Korolchenko, S. Voevoda, MATEC 86, $04038 \quad$ (2016) DOI:10.1051/matecconf/20168604038

45. V.V. Holschevnikov, A.N. Giletich, D.V. Ushakov, A.P. Parfenenko, Fire-andexplosion safety, 12 (2011)

46. V.V. Holschevnikov, Applied Engineering Research 10, 21 (2015) 